\title{
Service-Driven Growth Pattern In IT Industries And Contributing Factors: A New Pattern In The Korean Industrial Development Perspective
}

\author{
Duk Hee Lee, (E-mail: dhl@icu.ac.kr), Information and Communication University, South Korea
} Changi Nam, Information and Communication University, South Korea Junesuh Yi, Information and Communication University, South Korea

\begin{abstract}
This paper examines the pattern behind rapidly growing Korea's IT industries. Korea has characterized economic growth based on export demand rather than domestic demand at the traditional industries such as automobile, electronics, steel, and shipbuilding etc. However, the recent development of IT industry is indicating a different aspect from traditional sectors. The rapid growth in service demand is becoming a key factor in the rapid growth and high competitiveness of IT industry. A statistical estimation testing relationship between mobile telecommunication, Internet service, and wireless equipment, computer, strongly supports service-driven growth pattern of IT industry. Strong network externalities in demand side, government's demand promotion policies, residential environment, and users ' preferences, are main contributing factors to this new growth pattern.
\end{abstract}

\section{Introduction}

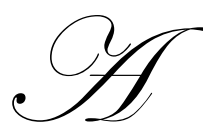

in the past.

n OECD report (2001) recognized Korea's rapid development in the information technology (IT) industry, especially in broadband Internet growth. The IT industry is now transforming a whole range of economic activity, just as the development of the steam engine, railways, and electricity did

The growth of the Korean IT sector has been achieved through both deregulation and competition. Over the past four years, the Korean government helped put the building blocks in place, laying high-speed lines and encouraging foreign investment in the IT sector. The government slashed regulations for Internet start-ups and deregulated the telecommunication industry. These initiatives have brought rapid improvement to Korea's telecommunication networks and rapid growth in mobile telephone services.

As a result, IT has contributed significantly to Korea's aggregate economic growth over the last few years. Network technologies based on telecommunications and the Internet are bringing the benefits of a network economy in which the more it is used, the more benefits it generates for all users. These network externalities on the demand side, given Koreans' high preference for high-tech devices, are becoming a strong driving force in the rapid growth of the

As a result, IT has contributed significantly to Korea's aggregate economic growth over the last few years. Network technologies based on telecommunications and the Internet are bringing the benefits of a network economy in which the more it is used, the more benefits it generates for all users. These network externalities on the demand side, given Koreans' high preference for high-tech devices, are becoming a strong driving force in the rapid growth of the Korean IT industry. 
Until now, the Korean economy has been characterized by export-pulling growth rather than domestic demand-pulling growth in traditional industries, such as automobiles and electronics. However, the recent development of the IT industry signals a move away from the traditional sectors. Domestic demand-led market forces based on service demand are becoming a key factor in the rapid growth and high competitiveness of the IT industry. Further, this demand-pulling growth in the IT industry is expected to contribute significantly to the Korean economy's sustained growth through the role of IT in its various influences on economic activity, as well as by the development of IT itself.

This paper sheds more light on some aspects of the "service-driven growth pattern" behind demand-pulling growth in the Korean IT industry. It first discusses "demand-pull" and "production-push" growth as economic development patterns. Next, it describes the rapid growth of the Korean IT industry and its contribution to the national economy. Then, it investigates some empirical evidence on demand-pulling growth, including some statistical estimation, and ends with a perspective of Korea's IT Industry and economic growth.

Until now, the Korean economy has been characterized by export-pulling growth rather than domestic demand-pulling growth in traditional industries, such as automobiles and electronics. However, the recent development of the IT industry signals a move away from the traditional sectors. Domestic demand-led market forces based on service demand are becoming a key factor in the rapid growth and high competitiveness of the IT industry. Further, this demand-pulling growth in the IT industry is expected to contribute significantly to the Korean economy's sustained growth through the role of IT in its various influences on economic activity, as well as by the development of IT itself.

This paper sheds more light on some aspects of the "service-driven growth pattern" behind demand-pulling growth in the Korean IT industry. It first discusses "demand-pull" and "production-push" growth as economic development patterns. Next, it describes the rapid growth of the Korean IT industry and its contribution to the national economy. Then, it investigates some empirical evidence on demand-pulling growth, including some statistical estimation, and ends with a perspective of Korea's IT Industry and economic growth.

\section{2. "Export-Pull" To "Domestic Demand-Pull"}

In the literature of industrial organization and economic development, the driving forces of technological innovation and growth have been discussed from two sides: the "supply-side" and the "demand-side". In the field of industrial organization, economists have been concerned with whether "demand-pull" on the demand side or "technology-push" on the supply side was the primary force behind technological innovation. Economists taking the former position argue that applied research and process or product innovation were mainly initiated by large and growing markets (Schmookler, 1962, Schmookler, 1966, Parker, 1972, Rosenberg, 1974). On the other hand, scholars taking the latter position insist that technological opportunity, such as R\&D intensity, knowledge, and science, led to technological innovation (Pakes and Schankerman, 1984, Scherer, 1965, Levin and Reiss, 1984, Levin et al., 1987). Both arguments are very dependent upon the sample industries studied, so that the relative merit of the two positions remains indeterminate.

However, in the field of economic development there are other issues more concerned with developing paths across different countries. In particular, from the standpoint of developing countries, "demand-pull" rather than "technology-push" has been more important for their initial economic development. "Technology-push" was a future target and their primary concern was how to implement a "demand-pull" strategy. That is, they had to choose "export demand-pull" or "domestic demand-pull based on exports". Most small and medium-sized countries, for example NICs (newly industrialized countries including Korea, Taiwan, Singapore, and Hong Kong), tended to choose the former as a development strategy because their domestic markets were small. They targeted foreign markets instead of the domestic market and used the production expansion strategy based on assembly line methods to meet export demand from abroad. In order to achieve this, they were first required to import the necessary raw materials and intermediate goods to assemble and export finished goods. Thereafter, they moved to substitute imports of intermediate goods or core technologies, producing them for themselves, and then ultimately exporting them to foreign countries. As a result, those countries have revealed the rapid economic growth based on manufacturing rather than service industries. 
Korea was not exceptional and was symbolized as a rapidly growing country using the strategy of "export demand-pulling growth". The traditional sectors, such as steel, automobiles, shipbuilding, and electronics, have remained in excess production capacity, relative to the export demand that led to Korea's past rapid economic growth. According to this strategy Korea was able to be competitive in the world market by keeping prices lower in the export market than in the domestic one. Although purchasing power in the domestic market inevitably remained below that in the export market, sustained creation of employment was possible as production capacity as a whole was enlarged. As a result, exports had been a major driving force of economic growth until at least the first half of the 1990s. For instance, the color television industry, a major export good of Korea, had grown rapidly due to the explosive growth of exports during the 1984-1996 period. Domestic demand had also contributed to the growth of production, but had not done so as much as exports had (Figure 1). Most studies found that the main source of the Korean economy's rapid growth in the 1962-1995 period was the export-oriented industrialization strategy. The ratio of exports to GNP increased to $27.7 \%$ in 1995 from only $0.1 \%$ in 1962 . The share of manufactured exports in the nation's exports also increased to $96.1 \%$ in 1995 from $27.0 \%$ in 1962 (Kim, 1997).

Figure 1: Color TV Production, Exports And Imports, And Domestic Demand

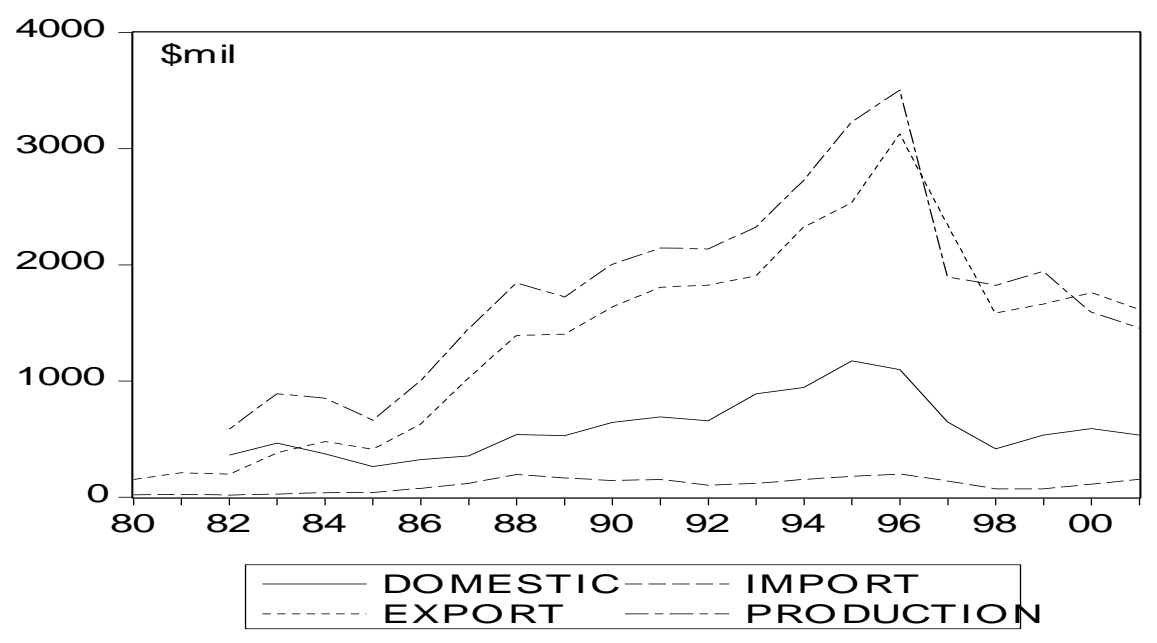

Source: Electronic Industry Association of Korea (EIAK), Korea Trade Information Service (KOTIS)

However, this growth pattern began to change gradually as the national economy developed and its competitiveness rose. This increased competitiveness rewarded each individual with higher income, creating more demand in the domestic market. In specific sectors, the growth rate of domestic demand began to surpass that of export demand and led to higher competitiveness. In particular, recent developments in the Korean IT industry are consistent with this new pattern of growth. Unlike the export-pulling growth in the traditional sectors, the IT industry is demonstrating a domestic demand-pulling growth pattern as well. Rapid growth in the IT service industry, such as wireless telecommunication and the Internet (high-speed broadband service), which have large consumption externalities, is becoming a strong driving force behind the recent growth of the Korean IT industry, and is influential in furthering economic recovery from the economic crisis of 1997.

This service-driven growth pattern is quite a new to Korea economy that has been accustomed to manufacturing-oriented growth pattern during the past decades. Several aspects are able to be specified as main contributing factors to this transformation: IT industries' characteristics, government policy transformation, consumers' preferences, and residential environment, and so on. These factors are directly or indirectly related to create "the servicedriven growth" as a emerging growth pattern in Korean industrial development perspective. 
Table 1: Ratio Of The IT Industry To GDP

(Units: 100 Million Won, Per Cent)

\begin{tabular}{|l|r|r|r|r|r|r|r|}
\hline & \multicolumn{1}{|c|}{$\mathbf{1 9 9 5}$} & \multicolumn{1}{c|}{$\mathbf{1 9 9 6}$} & \multicolumn{1}{c|}{$\mathbf{1 9 9 7}$} & \multicolumn{1}{c|}{$\mathbf{1 9 9 8}$} & \multicolumn{1}{c|}{$\mathbf{1 9 9 9}$} & \multicolumn{1}{c|}{ 2000 } & $\begin{array}{c}\text { Annual } \\
\text { Growth Rate }\end{array}$ \\
\hline GDP $^{1}$ (A) & $3,773,498$ & $4,184,790$ & $4,532,764$ & $4,443,665$ & $4,827,442$ & $5,170,966$ & 4.8 \\
\hline IT Industry $^{2}(\mathrm{~B})$ & 516,103 & 601,234 & 755,450 & 898,997 & $1,150,125$ & $1,417,016$ & 22.5 \\
\hline IT Services $^{\text {IT Equipment }}$ & 113,095 & 154,900 & 170,624 & 196,475 & 217,200 & 286,461 & 20.8 \\
Software & 386,256 & 419,638 & 549,792 & 655,688 & 867,938 & $1,051,582$ & 22.2 \\
\hline Ratio (B/A) & 16,752 & 26,696 & 35,034 & 46,834 & 64,987 & 78,973 & 36.4 \\
\hline
\end{tabular}

Source: Bank of Korea (BOK), Korea Association of Information and Telecommunication (KAIT)

Note: 1,2 GDP and IT production are in nominal values.

\section{Evidence Of Service-Driven Growth}

\subsection{Mobile Telecommunication Service And Equipment Industry}

Korea's telecommunication networks have been upgraded with sophisticated fiber-optic infrastructure. These networks connect businesses and individuals with reliable direct international links for telephone, fax and data networks. Korea is experiencing an explosive demand for PCS (Personal Communication Systems), and currently enjoys a high mobile telephone penetration rate. As of March 2002, over 30 million Koreans owned mobile phones, and the penetration rate is continuously increasing and has reached $63.8 \%$. This rapid growth in mobile telephone demand was stimulated by the Korean government's demand-promotion policies, and by the Korean people's desire for high-tech equipment. When mobile phone services were first introduced, service usage fees and handset prices were usually high due to the huge amount of fixed investment. This was an entry barrier to formulating a critical mass in the service market. Therefore, the Korean government allowed service providers to subsidize mobile phone handsets to make user access easier. As a result, it reduced the entry barrier to the service market and helped the rapid growth of the mobile phone service industry.

However, the government was worried that the demand-led market growth in the telecommunication service industry was repeating the import-inducing production pattern, which was a distinguishing feature in traditional sectors of the Korean economy. Excess momentum on the demand side inevitably increases the gap between demand and supply, and to narrow this gap, the Korean IT industry is depending heavily on imports of core technology. However, this demand-pulling growth in the wireless telecommunication service market has other aspects to it. It leads to high competitiveness and technological development in manufacturing industries, and it generates a synergy effect between the service and equipment industries. One of the reasons that it has different aspects to the traditional sectors may stem from a first-mover advantage in the wireless telecommunication industry. Korea commercialized its CDMA technology before any other country, and this technological innovation combined with the Korean public's readiness to adopt the 'next new thing' led to an explosive market growth. As the service market grew rapidly, accompanied by increasing returns due to the network externalities of the telecommunication service, the Korean market emerged as a test-bed for CDMA's new devices. Accordingly, this market growth resulted in positive feedback to further technological development and high competitiveness in the wireless telecommunication industry.

The relationship between the number of mobile phone subscribers and the domestic production rate in wireless telecommunication equipment provides strong evidence of this reasoning. The domestic production rate increases up to a certain level in line with the increase in the number of mobile phone subscribers (Table 2). There is no doubt that the explosive demand in mobile phone service contributed significantly to the higher growth in the telecommunication equipment industry. The manufacture of wireless telecommunication handsets is an example. It is also notable that the domestic production rate did not grow much higher after 1997. The average domestic production rate was as high as $87 \%$, and a marginal growth from that high level is not easy to accomplish. After 1999, service providers concentrated their investment in $3 \mathrm{G}$ wireless telecommunication services, inducing large imports of equipment and facilities. Those factors seemed to contribute to the slow growth in the domestic production rate. 
Table 2: Mobile Phone Subscribers, Domestic Production Rate, And Competitiveness In Wireless Telecommunication Equipment (Units: Million, Per Cent)

\begin{tabular}{|l|c|c|c|c|c|c|c|}
\hline & $\mathbf{1 9 9 4}$ & $\mathbf{1 9 9 5}$ & $\mathbf{1 9 9 6}$ & $\mathbf{1 9 9 7}$ & $\mathbf{1 9 9 8}$ & $\mathbf{1 9 9 9}$ & $\mathbf{2 0 0 0}$ \\
\hline Mobile Phone Subscribers & 0.96 & 1.64 & 3.18 & 6.83 & 13.98 & 23.44 & 26.82 \\
\hline Domestic Production Rate $^{1}$ & 31 & 57 & 69 & 88 & 89 & 88 & 84 \\
\hline Trade Specialization Index $^{2}$ & -8.47 & -3.27 & -16.83 & 22.43 & 49.01 & 58.21 & 63.53 \\
\hline
\end{tabular}

Source: Korea Association of Information and Telecommunication (KAIT)

Notes: 1. Domestic production rate $=1-($ import/domestic demand $)$.

2. Trade Specialization Index $=((\text { export }- \text { import }) /(\text { export }+ \text { import }))^{*} 100$. The value of the index is between -100 and 100 . If the value is close to 100 , it represents an export specialization that is highly competitive while close to -100 means import specialization.

The trend in competitiveness of the wireless telecommunication equipment industry provides other evidence of the demand-pulling growth in the Korean IT industry. It is seen that the competitiveness in the wireless telecommunication equipment continued to increase as the number of mobile phone subscribers increased during 1994-2000. Until 1997, when the PCS service was introduced, mobile phone subscriber numbers did not show a sharp increase. Accordingly, competitiveness in the wireless telecommunication equipment industry did not rise quickly, and even decreased during 1995-1996. After 1997, however, with a sharp increase in subscribers, competitiveness began to increase sharply. After 1999, again, competitiveness was slow to move in accordance with subscriber numbers (Table 2). This close relationship strongly accounts for one aspect of the service-driven growth in the Korean IT industry.

\subsection{Internet Service And The Computer Industry}

Strong demand for Internet access has resulted in much higher growth in Internet user numbers in Korea than in the rest of the world. From 1995 to 2000, the average annual growth of Internet users in Korea was $127 \%$, double the world average of $62 \%$. As of June 2001, Internet users in Korea totaled over 22 million, or about $51.5 \%$ of the country's population (Table 3). This figure grew 16.7\% from December 2000 to June 2001 to reach 22.2 million. While Korea ranks fifth in terms of absolute numbers, it ranks fourth in terms of penetration of the entire population (Netsizer, April 2001).

In addition, telecommunication networks have been upgraded continuously in terms of both speed and service. As of March 2001, more than eight million homes now have high-speed Internet access. Moreover, the quality of Internet services has improved. DSL service users surpassed CATV users in May 2000 and had a 78.3 per cent share of total high-speed Internet users as of March 2002.

According to an OECD report (2001), Korea is the leading country for broadband Internet connections, far exceeding both Canada (ranked second) and the United States (ranked third). The 8.2 million broadband connections in Korea (March 2002) are the result of fierce competition among providers of cable Internet and DSL, which turns ordinary telephone lines into broadband server lines. There are several factors behind this rapid growth in highspeed Internet access in Korea. The Korean government's policy emphasizing facilities competition among the service providers rather than regulations, such as "unbundling", has had a great influence on the remarkable growth in high-speed Internet services. The fierce competition among the service providers (e.g., Korea Telecom, Hanaro Telecom, Thrunet) attracts more people to access the service by competing with, for example, price discounts, fixed rate fees, and tied sales (service bundling). As a result, the service providers have been able to make large profits, and so by attaining a critical mass in the market, investment for service upgrading has been possible. It thus attracted more and more people to access high quality services, which provided an opportunity for positive feedback between policy and service demand.

The Internet is not just a technology. It has become an integral part of society and daily life in Korea. The government has connected all of the country's 43,000 elementary, middle, and high schools to the Internet, and there are at least 20,000 private Internet cafés. People who believe strongly in education have also invested in PCs for their homes. 
Table 3: Internet Users, Number Of Pcs, And Competitiveness In The Computer Industry ${ }^{4}$ (Units: 1000s)

\begin{tabular}{|c|c|c|c|c|c|c|c|c|}
\hline & 1995 & 1996 & 1997 & 1998 & 1999 & 2000 & 2001 & $\begin{array}{c}\text { Average } \\
\text { Growth Rate }^{1}\end{array}$ \\
\hline $\begin{array}{l}\text { Internet users } \\
\text { (world total) }\end{array}$ & $\begin{array}{c}366 \\
(34,600)\end{array}$ & $\begin{array}{c}731 \\
(59,850)\end{array}$ & $\begin{array}{c}1,63 \\
(99,960)\end{array}$ & $\begin{array}{c}3,103 \\
(151,500)\end{array}$ & $\begin{array}{c}10,860 \\
(227,500)\end{array}$ & $\begin{array}{c}19,040 \\
(327,070)\end{array}$ & $\begin{array}{c}22,226^{2} \\
(-)\end{array}$ & 127 \\
\hline No. of PCs & 5,349 & 6,304 & 6,931 & 8,269 & $11,530^{3}$ & 15,000 & - & 22.9 \\
\hline $\begin{array}{l}\text { Trade Specialization } \\
\text { Index }\end{array}$ & 17 & 13 & 22 & 41 & 39 & 30 & 30 & - \\
\hline
\end{tabular}

Source: Korea Network Information Center (KRNIC), National Computerization Agency (NCA), National Statistical Office (NSO), Korea Trade Information Service (KOTIS)

Notes: 1. 1995-2000 average growth rate

2. The number of Internet users as of June 2001

3. Public sector's PCs are excluded in 1999

4. The computer industry includes computers, secondary memory units, printers, monitors, computer peripheral devices, computer parts, and data recorders.

This high growth of PC demand is also linked to the high competitiveness of the Korean computer industry. According to information in the computer industry's trade specialization index, competitiveness has been rising gradually since 1995, which has allowed strong export specialization. Despite variations in the index during some periods, the index indicated an upward trend as a whole during 1995-2001. Therefore, it can be argued that Korea's high demand for Internet services has resulted in a gradual improvement of the computer industry's competitiveness due to the large demand for PCs. This relationship will be statistically tested in the rest of this paper.

\subsection{Statistical Test: The Granger Causality Test}

To see whether one variable leads or lags behind another variable, statistically testing the causal direction between the two variables is necessary. We consider a relatively simple test of causality, the Granger Causality Test. We first test whether the growth in mobile telecommunication subscriptions causes the competitiveness of the wireless telecommunication equipment industry, and secondly whether the growth in Internet user numbers causes the competitiveness of the computer industry.

The test involves estimating the following regressions:

$Y_{t}=\sum_{i=1}^{n} \alpha_{i} X_{t-i}+\sum_{j=1}^{n} \beta_{j} Y_{t-j}+u_{t}$

First, we regress current $\mathrm{Y}$ on all lagged $\mathrm{Y}$ terms and other variables, if any, but do not include lagged $\mathrm{X}$ variables in the regression. From this regression we obtain the restricted residual sum of squares, $\mathrm{RSS}_{\mathrm{R}}$. Second, we run the regression including lagged $\mathrm{X}$ terms and obtain the unrestricted residual sum of squares, $\mathrm{RSS}_{\mathrm{UR}}$. Third, we set up the null hypothesis, $H_{0}: \Sigma \alpha_{i}=0$. Fourth, to test this hypothesis, we apply the $F$ test:

$$
F=\frac{\left(R S S_{R}-R S S_{U R}\right) / m}{R S S_{U R} /(n-k)}
$$

which follows the $F$ distribution with $m$ and $(n-k)$ degrees-of-freedom if the null hypothesis is true. The term $m$ represents the number of lagged $\mathrm{X}$ terms and $k$ is the number of parameters estimated in the unrestricted regression.

Regarding the first test, we use the quarterly growth rate of mobile phone subscribers (SNQR) as the X variable and the Trade Specialization Index of the wireless telecommunication equipment industry (TITWQ) as the Y 
variable, for the period from the second quarter of 1996 to the first quarter of 2002. We estimate the following two regressions to see if the two variables cause each other:

$$
\begin{gathered}
T I T W Q_{t}=\sum_{i=1}^{n} \alpha_{i} S N Q R_{t-i}+\sum_{j=1}^{n} \beta_{j} T I T W Q_{t-j}+u_{1 t} \\
F=2.81 \\
S N Q R_{t}=\sum_{i=1}^{n} \gamma_{i} T I T W Q_{t-i}+\sum_{j=1}^{n} \theta_{j} S N Q R_{t-j}+u_{2 t} \\
F=1.35
\end{gathered}
$$

The computed $F$ values are 2.81 and 1.35 . Both are not highly significant. However, because 2.81 exceeds the critical $\mathrm{F}$ value (2.70) at the $10 \%$ level, the null hypothesis is rejected at this level of significance, so that the growth rate of mobile phone subscribers (SNQR) is concluded to cause the Trade Specialization Index of the wireless telecommunication equipment industry (TITWQ).

\section{Figure 2: Quarterly Growth Rate Of Mobile Phone Subscribers (SNQR) And Trade Specialization Index Of Wireless Telecommunication Equipment Industry (TITWQ) \\ (The Second Quarter Of 1996 To The First Quarter Of 2002)}

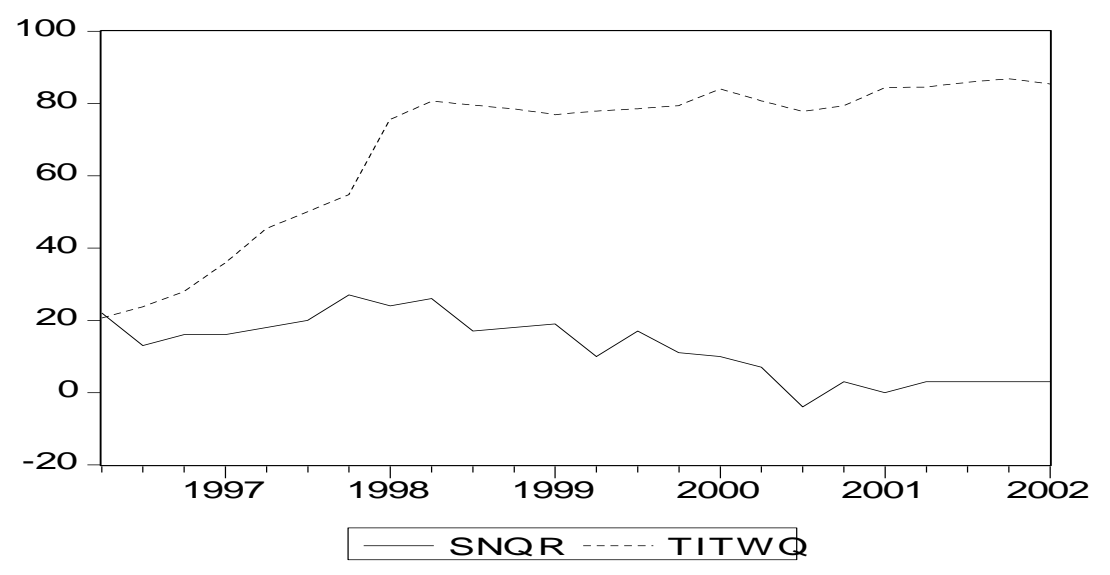

Similarly, we do the same test for the causal direction of the growth in Internet users and the competitiveness of the computer industry, using the monthly growth rate of Internet users (IUR) and the Trade Specialization Index of the computer industry (TICT) for the period from January 1999 to December $2001^{1}$. Estimating the following two regressions provides a very significant result. The $F$ values of the regressions are 4.63, 0.78, and 4.63. Only the 0.78 value is insignificant. This result strongly supports the view that the growth rate of Internet users (IUR) causes the Trade Specialization Index of the computer industry (TICT). The model and results in detail are as follows:

$$
\begin{gathered}
T I C T_{t}=\sum_{i=1}^{l} \lambda_{i} I U R_{t-i}+\sum_{j=1}^{l} \delta_{j} T I C T_{t-j}+u \varepsilon_{1 t} \\
F=4.63
\end{gathered}
$$

\footnotetext{
1 Since neither monthly nor quarterly data on Internet users before 1999 are available, we use monthly data on both Internet users and the Trade Specialization Index of the computer industry after 1999.
} 


$$
\begin{gathered}
I U R_{t}=\sum_{i=1}^{l} \eta_{i} T I C T_{t-i}+\sum_{j=1}^{l} \tau_{j} I U R_{t-j}+\varepsilon_{2 t} \\
F=0.78
\end{gathered}
$$

\section{Figure 3: Monthly Growth Rate Of Internet Users (IUR) And Trade Specialization Index Of The Computer Industry (TICT) (January 1999 To December 2001)}

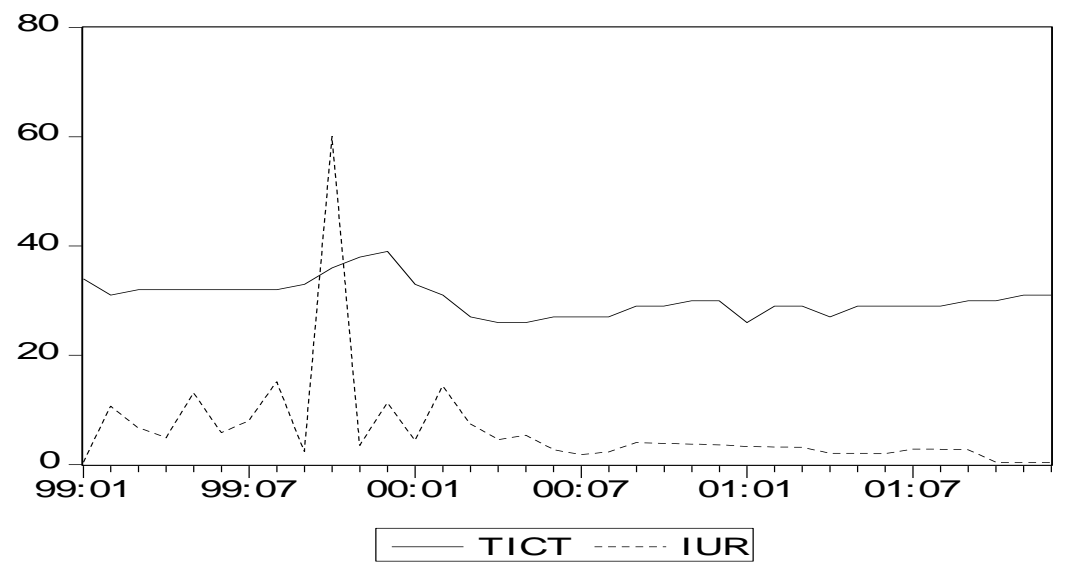

Both tests reveal that the growth in the numbers of mobile phone subscribers causes the competitiveness of the wireless telecommunication equipment industry, and that the growth in Internet users causes the competitiveness of the computer industry. This is statistical evidence in favor of demand-pulling growth in the Korean IT industry.

Table 4: Basic Statistics Of Variables

\begin{tabular}{|l|c|c|c|c|c|}
\hline & Mean & Stan. Dev. & Min & Max. & No. \\
\hline SNQR & 11.952 & 9.097 & -4.0 & 26.0 & 24 \\
\hline TITWQ & 74.343 & 14.534 & 20.6 & 86.8 & 24 \\
\hline IUR & 6.285 & 10.377 & 0.35 & 60.07 & 36 \\
\hline TICT & 30.212 & 3.170 & 26.0 & 39.0 & 36 \\
\hline
\end{tabular}

Source: Korea Ministry of Information and Communication (MIC), Korea Network Information Center (KRNIC), Korea Trade Information Service (KOTIS)

\section{Contributing Factors}

Several aspects have been mentioned regarding the service-driven growth of IT industry. First, IT industries' characteristics, that is, network externalities matter with the rapid growth in service demand. IT service industries deal with network goods that show large network externalities in consumption side, compared to other nonnetwork goods in traditional service industries. Mobile telecommunication and Internet service are two-way networked and hence their subscribers grow more drastically than one-way network industries such as broadcasting service $^{2}$. Since two-way network creates the larger network externalities than one-way network, once the subscribers pass a critical mass point their growth begins to accelerate in the increasing returns manner.

2 In the n-node two-way network, there are n(n-1) links. An additional node creates $2 \mathrm{n}$ new links. However, in the n-node one-way network case, an additional node creates $n$ new links. See Rohlfs(1974) about the details. 
Figure 4: Wireless Telecommunication Subscribers

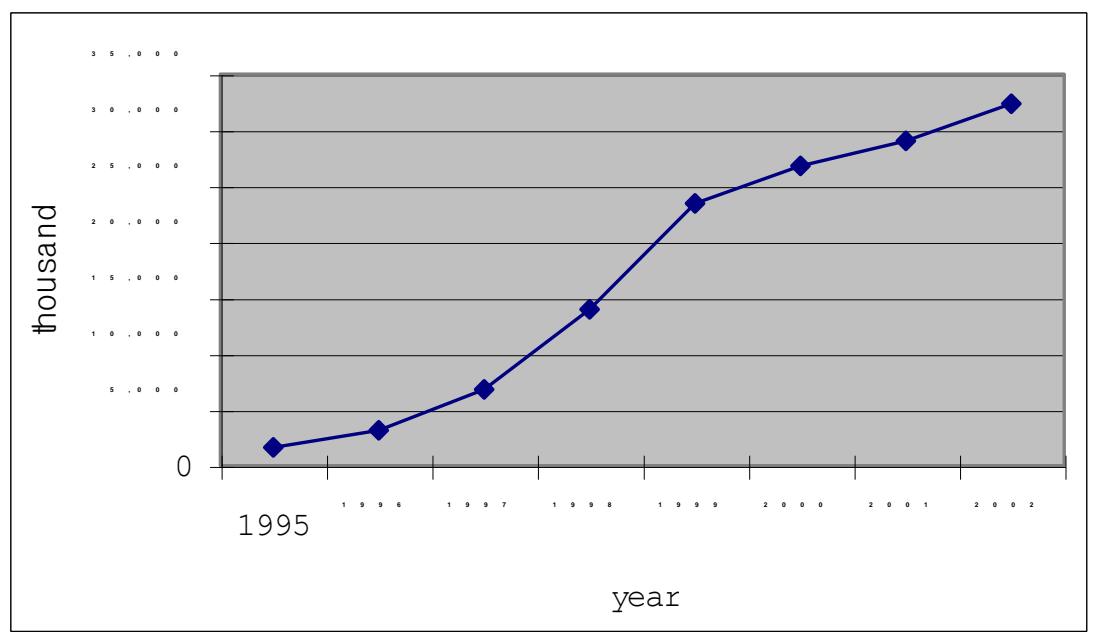

This radical growth in service demand led to the higher domestic demand on hardware equipments. However, since the quality demanded is well advanced in the world, service providers have to rely on domestic technology innovation through R\&D rather than imports of necessary technology and equipments (Table 2$)^{3}$. This is a different pattern from the past in that companies had to rely on the imports of necessary technology and equipments to meet the rapidly growing exports that were originated from advanced service quality in developed countries.

Second, government policy transformation from supply-side to demand-side also contributed to create the service-driven growth pattern. Government of course implemented supply-side policies as had done in the conventional policies, for examples, regulating the telecommunication industry, building telecommunication network infrastructure, boosting venture business, and so on. However, government's demand promotion policies contributed more significantly to bear the service-driven growth pattern. In particular, subsidizing mobile phone handsets resulted a high demand on mobile telecommunication subscription and hence a high penetration rate. The handsets subsidy policy implemented during October 1997 to May 2000. The number of subscribers showed a similar trajectory with the handsets subsidy policy: the rapid growth period of the subscriber coincided with the subsidy period (Figure 4).

The Informatization Education Program for 10 Million People was another type of the demand promotion policies. According to this program each government ministry has one's own program for specific group of people who have difficulties to access to the information society. For an instance, the Ministry of Information and Communication runs the Internet Education Program for 1 Million Housewives. The Ministry is able to subsidize some portion of education fee by this program. This program achieved a good performance, and thereafter diffused over nationwide and was adopted as information programs of many local governments. With this program, National PC Popularization was also adopted. The purpose is to provide the public with lower-priced PC by allowing the designated PC makers to manufacture and sell the National PC.

Third, the residential environment and consumer preferences became a critical factor to the transformation of growth pattern. The high population density in most Korean Cities and induced congestion increase social uncertainty and instability. This will eventually lower total productivity by increasing general production costs including logistic costs. To cope with this inefficiency, individual and organization are more likely to consume mobile telecommunication and high-speed Internet service than do in other less density countries. The high population density was an advantage to the service providers because about $48 \%$ of total population lives at high-story apartments and

\footnotetext{
3 Therefore, the domestic production rate showed an increase over the period in Table 2.
} 
this generated high profits in short term with relatively lower investment costs. A feature of Korean public's preferences is the excess momentum of its consumption side, where consumption rather than production goes in advance and leads to a high consumption competition not to be excluded from a group, based on the Confucian Collectivism. This accounts for the Korean public's readiness to adopt "new thing".

\section{Conclusions And Policy Implications}

The statistical evidence is that the domestic demand-pulling effect driven by service sector is becoming a driving force in the rapid growth of the Korean IT industry. This feature of the IT industry is somewhat different from that of the traditional sectors in the Korean economy. As the Korean government has emphasized an exportdriven economic policy to develop a domestic production base, production has been more advanced than domestic consumption in terms of both quantity and quality in those sectors. However, as the scale of national economic activity increased and as competitiveness strengthened, this policy had to change to a more market-oriented one. With policy emphasizing change from a production-driven to a market-driven economy, demand-pulling growth phenomena began to diffuse gradually through the Korean economy as a whole. In particular, the IT industry has been positioning itself as a leader in Korean industry.

This service-led growth also stems from the network externality property of the IT industry itself. Network externality is one of the main driving forces in the dramatic growth of the network industry, such as the wireless telecommunication service and the Internet. This is quite different from the traditional sectors (non-network industries) in that the former has stronger network externalities than the latter in service consumption, which means that demand for IT services grows increasingly while demand for traditional services declines correspondingly. There is an increasing gap between the service and manufacturing sectors in the former industry. Accordingly, more rapid growth in the service sectors is leading growth in the manufacturing sectors in the IT industry. This eventually accounts for the service-driven growth feature of the Korean IT industry, which is accelerated by the government's demand promotion policy and Koreans' high demand for new products.

The Korean IT industries' experience implies that policies should be consistent with the characteristics of technologies or industries and timely implemented. IT industries and IT-driven economy is deeply related to the concept of network economics in which network externalities, increasing returns principle, path dependent process, critical mass, etc. are more dominant than in the conventional economy. The policy examples mentioned such as the Mobile Telecommunication Handsets Subsidy and other demand promotion policies are directly or indirectly relevant with these basic concepts. It is also noted from the Korean experience that economy and industries are well performed when the policies are specified reflecting country specific social and cultural features.

Finally this ongoing feature of the Korean IT industry provides some perspectives for national economic development strategy. Does IT guarantee prosperity for an economic latecomer? Given that IT development is an ongoing process, the answer is indeterminate. This is likely to remain a major question, although the current jargon of "winner takes all," "first mover advantage," "path-dependent process" and "increasing global returns" suggests that prosperity, as always, will be difficult and is never guaranteed. On the other hand, the reality of "technological paradigm shifts" and the "fast pace of technological progress" suggests that opportunities exist for followers to take the lead in IT development. However, the argument that followers need to compromise on both long and short-term $R \& D$ is food for thought, as long-term R\&D may be useful in preparing to become a leader, while the latter may be more useful in a catching up process.

\section{References}

1. Bank of Korea (BOK), http://www.bok.or.kr.

2. Electronic Industry Association of Korea (EIAK), http://www.eiak.org.

3. Kim, Kwangsuk, 1997. Accounting for Rapid Economic Growth in Korea, 1963-1995, Korea Development Institute.

4. Korea Association of Information and Telecommunication (KAIT), "Statistics of Information and Telecommunication Industry", http://www.kait.or.kr/index.php. 
5. Korea Network Information Center (KRNIC), Internet Statistics, http://stat.nic.or.kr/iusr.html.

6. Korea Trade Information Service (KOTIS), http://www.kotis.net/.

7. Levin, R. C. and Reiss, P. C., 1984. "Tests of a Schumpeterian Model of R\&D and Market Structure", in Griliches, Z. ed., R\&D, Patents, and Productivity. Chicago: University of Chicago Press for the National Bureau of Economic Research.

8. Levin, R. C., Klevorick, A. K., Nelson, R. R. and Winter, S. G., 1987. "Appropriating the Returns from Industrial R\&D”, Brookings papers on Economic Activity, 783-820.

9. Ministry of Information and Communications (MIC), April 2001. "Information Technology Overview", http://www.mic.go.kr.

10. National Computerization Agency (NCA), "Information Statistics", http://www.nca.or.kr/stat.

11. National Statistical Office (NSO), http://www.nso.go.kr.

12. Netsizer, April 2001. "Current Statistics for Top Internet Penetrated Countries”, www.netsizer.com/daily/TopCountry.html.

13. OECD, 2001. Drivers of Growth: Information Technology, Innovation and Entrepreneurship.

14. Pakes, A. and Schankerman, M., 1984. "An Exploration into the Determinants of Research Intensity", in Griliches, Z. ed., R\&D, Patents, and Productivity. Chicago: University of Chicago Press for the National Bureau of Economic Research.

15. Parker, W. N., 1972. "Agriculture”, in Davis, L. E., R. A. Easterlin, and W. N. Parker, eds., American Economic Growth: An Economist's History of the United States. New York: Harper and Row.

16. Rohlfs, J., 1974. "A Theory of Interdependent Demand for a Communication Service", Belle Journal of Economics 5, 16-37.

17. Rosenberg, N., 1974. "Science, Innovation, and Economic Growth”, Economic Journal 84, 90-108.

18. Scherer, F. M., 1965. "Firm Size, Market Structure, Opportunity, and the Output of Patented Inventions", American Economic Review 55, 1097-1125.

19. Schmookler, J., 1962. "Economic Sources of Inventive Activity”, Journal of Economic History 22, 1-10.

20. Schmookler, J., 1966. Invention and Economic Growth. Cambridge, Mass.: Harvard University Press.

Notes 
Notes 